AperTO - Archivio Istituzionale Open Access dell'Università di Torino

\title{
Management of older adults with multiple myeloma
}

\section{This is the author's manuscript}

Original Citation:

Availability:

This version is available http://hdl.handle.net/2318/145255

since 2023-02-12T09:33:50Z

Published version:

DOI:10.1016/j.blre.2013.04.001

Terms of use:

Open Access

Anyone can freely access the full text of works made available as "Open Access". Works made available under a Creative Commons license can be used according to the terms and conditions of said license. Use of all other works requires consent of the right holder (author or publisher) if not exempted from copyright protection by the applicable law. 


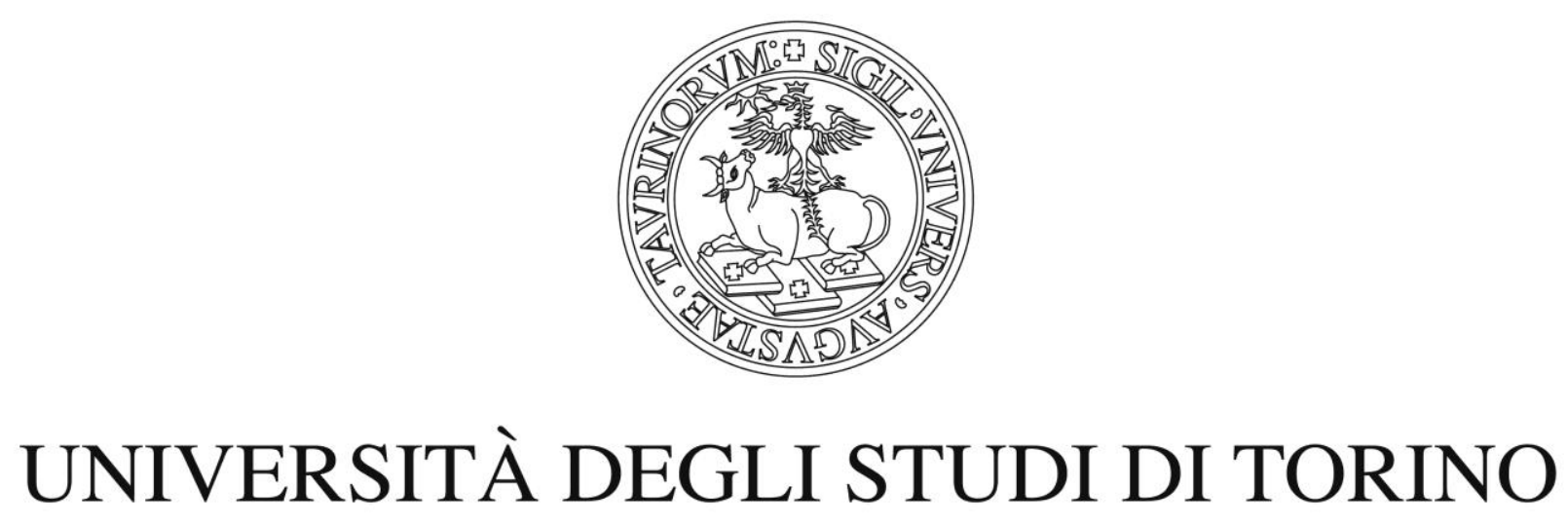

This is an author version of the contribution published on:

Questa è la versione dell'autore dell'opera:

[Blood Rev. 2013 May;27(3):133-42. doi: 10.1016/j.blre.2013.04.001. Epub 2013 Apr 25.]

The definitive version is available at:

La versione definitiva è disponibile alla URL:

[http://www.sciencedirect.com.offcampus.dam.unito.it/science/article/pii/S026896 0X13000179] 


\title{
Management of older adults with multiple myeloma
}

\author{
Antonio Palumbo', Roberto Mina \\ Myeloma Unit, Division of Hematology, University of Torino, Torino, Italy
}

\begin{abstract}
Two-thirds of patients with multiple myeloma are aged 65 years or more and the prevalence of multiple myeloma in elderly patients is expected to rise in the next future. Patients older than 65 years are usually considered ineligible for transplantation. The introduction of novel agents, such as the immunomodulatory drugs thalidomide and lenalidomide and the proteasome inhibitor bortezomib, combined with conventional chemotherapy, has radically changed the treatment paradigm of elderly patients and improved outcome. A sequential approach, consisting of an induction regimen associated with a high rate of complete response, followed by consolidation/maintenance therapy, induces a profound cytoreduction and delays relapse, thus improving survival. Novel agents associated with reduced-intensity autologous transplant showed to be safe and effective in fit elderly patients. Patients older than 75 years or vulnerable ones are more susceptible to adverse events that negatively affect treatment adherence and outcome. In this setting, less toxic regimens and appropriate dose reductions should be adopted. Here we provide an overview of novel agent-based treatment strategies for elderly patients with multiple myeloma.
\end{abstract}

\section{Keywords}

- Multiple myeloma;

- Thalidomide;

- Lenalidomide;

- Bortezomib;

- Fit;

- Unfit;

- Elderly patients

\section{Introduction}

Multiple myeloma (MM) is a neoplastic plasma-cell disorder characterized by clonal proliferation of malignant plasma cells in the bone marrow microenvironment, monoclonal protein in the blood or urine, and associated organ dysfunction (Table 1). ${ }^{1}$ Treatment should be immediately started in presence of a symptomatic disease, typically characterized by the occurrence of at least one of the CRAB symptoms (C: hypercalcemia $(>11.5 \mathrm{mg} / \mathrm{dL}) ; \mathrm{R}$ : renal failure (serum creatinine $>1.73 \mathrm{mmol} / \mathrm{L}$ ); A: anemia (hemoglobin $<10 \mathrm{~g} / \mathrm{dL}$ or $>2 \mathrm{~g} / \mathrm{dL}$ below the lower limit of normal); and B: bone disease (lytic lesions, severe osteopenia or pathologic fractures). In case of asymptomatic disease, only close monitoring is recommended. 
Table 1. Diagnostic criteria.

\begin{tabular}{|c|c|}
\hline Diagnosis & Diagnostic ariteria \\
\hline $\begin{array}{l}\text { Monoclonal gammopathy } \\
\text { of undetermined } \\
\text { significance (MGUS) }\end{array}$ & $\begin{array}{l}\text { - Serum monoclonal protein (IgG or IgA) }<3 \mathrm{~g} / \mathrm{dL} \\
\text { - Clonal bone marrow plasma cells }<10 \% \\
\text { - Absence of myeloma-related organ impairment: } \\
\text { hyperCalcemia, Renal insufficiency, Anemia and } \\
\text { lytic Bone lesions (CRAB) and symptoms. }\end{array}$ \\
\hline $\begin{array}{l}\text { Smoldering multiple } \\
\text { myeloma (asymptomatic } \\
\text { multiple myeloma) }\end{array}$ & $\begin{array}{l}\text { - Serum monoclonal protein (IgG or IgA) } \geq 3 \mathrm{~g} / \mathrm{dL} \\
\text { and/or clonal bone marrow plasma cells } \geq 10 \% \\
\text { - Absence of myeloma-related organ impairment: } \\
\text { hyperCalcemia, Renal insufficiency, Anemia and } \\
\text { lytic Bone lesions (CRAB) and symptoms. }\end{array}$ \\
\hline $\begin{array}{l}\text { Symptomatic Multiple } \\
\text { Myeloma }\end{array}$ & $\begin{array}{l}\text { - Clonal bone marrow plasma cells } \geq 10 \% \\
\text { - Monoclonal protein in serum and/or urine a } \\
\text { - Presence of myeloma-related organ impairment } \\
\text { and symptoms: } \\
\text { [C] Hypercalcemia: (serum calcium }>10.5 \mathrm{mg} / \mathrm{L} \\
\text { or upper limit of normal) } \\
\text { [R] Renal insufficiency: (serum creatinine }> \\
2 \mathrm{mg} / \mathrm{dL} \text { ) } \\
\text { [A] Anemia (hemoglobin }<10 \mathrm{~g} / \mathrm{dL} \text { or } \\
2 \mathrm{~g}<\text { normal) } \\
\text { [B] Bone disease: lytic lesions, severe osteopenia } \\
\text { or pathological fracture }\end{array}$ \\
\hline Solitary plasmacytoma & $\begin{array}{l}\text { - Biopsy-proven plasmocytoma of bone or soft } \\
\text { tissue in one site only with negative radiographs } \\
\text { or MRI outside the primary site. } \\
\text { - Absence of clonal plasma cells in bone marrow. } \\
\text { - Absence of myeloma-related organ impairment: } \\
\text { hyperCalcemia, Renal insufficiency, Anemia and } \\
\text { lytic Bone lesions (CRAB) and symptoms. }\end{array}$ \\
\hline
\end{tabular}

${ }^{a}$ Except in patients with true non-secretory multiple myeloma; MRI, magnetic resonance imaging.

In the last decades the introduction of autologous stem-cell transplantation (ASCT) and novel agents, such as the immunomodulatory drugs (IMiDs) thalidomide and lenalidomide, and the proteasome inhibitor bortezomib, radically changed the treatment paradigm of MM, extending overall survival (OS). ${ }^{1}$ The estimates of 5-year relative survival of patients with MM in the United States from 1990-1992 to 2002-2004 showed that this benefit was evident in patients aged less than 50 years (5-year relative survival: $45-57 \%$ ) and in those aged 50-59 years (5-year relative survival: 39-48\%), it was less pronounced in those aged 60-69 years (5-year relative survival: $31-36 \%$ ), and it was absent in those older than 70 years of age (5-year relative survival: $27-29 \%){ }^{2}$ The use of more sophisticated imaging techniques, such as computed tomography (CT), magnetic resonance imaging (MRI) and positron emission tomography (PET) may help to better define osteolytic lesions and identify the disease early.

Clonal heterogeneity and genomic instability typical of myeloma cells are responsible for clinical relapse and refractory disease. ${ }^{3}$ The clinical heterogeneity of $\mathrm{MM}$ is due to the coexistence of different myeloma clones with various mutation patterns and subsequent biological and clinical behaviors. According to a Darwinian evolutionary model, the sequence in which therapies are 
performed may induce different biological responses in the different clones, with the eradication of an indolent clone and the growth of a more aggressive one. ${ }^{4}$ This will negatively affect post-relapse survival. In the future, a deeper knowledge of the biology of MM cells in the clinical setting should guide the choice of therapy to improve outcome and prevent the occurrence of refractory disease. ${ }^{5}$

At diagnosis, induction therapy has a greater impact on survival duration, in comparison with salvage treatment performed at relapse. Novel agents can be combined with conventional chemotherapy to create multi-drug regimens that may better overcome clonal heterogeneity of myeloma. At diagnosis, the presence of sensitive tumor may increase the chance of deep responses of a longer duration and decrease the risk of adverse events with better quality of life and lower related health care cost ${ }^{6}$; by contrast, in later phases, the presence of resistant disease significantly decreases the proportion of responses and increases the risk of adverse events, negatively affecting both quality of life of patients and health care costs. ${ }^{7}$

The depth of response and its duration are important prognostic factors in MM: the achievement of a complete response (CR), with either negative immunofixation or negative minimal residual disease (MRD), induces longer progression-free survival (PFS) and overall survival (OS), both in young and elderly patients. An analysis performed on $4990 \mathrm{MM}$ patients treated with conventional chemotherapy and ASCT showed that patients achieving CR after induction had significantly longer PFS and OS compared to those who obtained a partial response (PR) only (59-89 vs. 3968 months). ${ }^{8}$ Similarly, attaining a CR proved to be an independent predictor of longer survival in elderly patients treated with both conventional chemotherapy and novel agents. ${ }^{9}$ Therefore, combination regimens and treatment strategies with high probability of CR should be adopted, unless a high risk of serious adverse events suggests a more gentle approach.

Continuous treatment with novel agents until disease progression or intolerability increased the depth of response and extended both PFS and recently OS. ${ }^{[10], ~[11], ~[12], ~[13] ~ a n d ~[14] ~ L e n a l i d o m i d e ~}$ maintenance after melphalan-prednisone-lenalidomide (MPR) induction reduced the risk of progression by $66 \%$ compared with no maintenance, with no significant increase in toxicity. ${ }^{14}$ This advantage was observed regardless of age. Maintenance with bortezomib plus thalidomide (VT) after bortezomib-based induction proved to be effective and well tolerated, and extended median PFS to 36-39 months. ${ }^{[10], ~[12], ~[13], ~[15], ~[16] ~ a n d ~[17] ~ I n ~ a ~ l a n d m a r k ~ a n a l y s i s ~ a t ~ s t a r t ~ o f ~ m a i n t e n a n c e, ~ i n ~}$ patients 65 to 75 years of age, VT maintenance after bortezomib-melphalan-prednisonethalidomide induction reduced the risk of death by $37 \%$ compared with standard VMP without maintenance. $^{10}$

Treatment discontinuation due to therapy-related adverse events is another important factor that negatively impacts outcome. Indeed, discontinuations translate into dose-reduction and reduced cumulative dose-intensity, affecting efficacy of therapies. This is particularly evident in patients older than 75 years, in whom adverse events are a major cause of treatment discontinuation, especially with multi-drug regimens. ${ }^{14}$ In this subset of patients, the evaluation of frailty and disability is essential to propose tailored therapy in order to reduce treatment discontinuation rate and to deliver the highest cumulative dose-intensity. ${ }^{18}$ Three-drug regimens with an acceptable toxicity profile are more suitable for fit patients, while 2-drug regimens with a more tolerable toxicity profile should be adopted for vulnerable patients to decrease discontinuation, thus allowing patients to stay on therapy for a longer period. ${ }^{19}$

In conclusion, major therapeutic efforts should be concentrated at diagnosis, when the disease is sensitive. Regimens associated with high CR rate and continuous therapy should be adopted. Treatment toxicity and discontinuation rate should be reduced in order to decrease the frequency of 
adverse events, maximize treatment efficacy and improve outcomes. In unfit patients, a gentler approach to minimize adverse events and preserve patient's quality of life is suggested.

\section{Epidemiology}

MM comprises $1 \%$ of all cancers and $13 \%$ of hematologic malignancies. Median age at diagnosis is 70 years; $35 \%$ of patients are younger than 65 years, $28 \%$ aged between 65 and 74 years and $37 \%$ are older than 75 years. ${ }^{[20]}$ and ${ }^{[21]}$ The incidence and prevalence of MM increase with age: the annual age-adjusted incidence rises from $<1 / 100,000$ for subjects younger than 40 years, to $>40 / 100,000$ for those older than 80 years; the annual prevalence of MM in patients aged 65-74 is approximately $31 / 100,000$ and rises to $46 / 100,000$ in patients aged older than 75 years. Both the incidence and prevalence of MM in elderly patients are expected to grow in the next future due to the increase in the life expectancy of the general population and the improved survival times achieved with the introduction of novel agents. Although $\mathrm{MM}$ is typical of the elderly, these patients are underrepresented in clinical trials because comorbidities and frailty often prevent them from being enrolled in experimental protocols. ${ }^{22}$

\section{Definition of fit and unfit patients}

The standard age cut-off of 65 years used to evaluate patient's eligibility to ASCT is no longer valid, as chronological age and biological age may greatly differ, especially in the geriatric population. Aging is associated with modifications in the organ functions that may reduce the tolerability of therapy. The presence of comorbidities, frailty and disability should be considered when planning treatment as they may negatively impact the outcome of elderly patients. Comorbidity is defined by the presence of $\geq 2$ concomitant medically diagnosed diseases. Frailty is a clinical entity characterized by the presence of $\geq 3$ core elements of frailty: weakness, weight loss, low physical activity, poor endurance and slow gait speed. Disability is defined by limitations in carrying out common daily activities typical of independent living, due to physical or mental impairment. $^{[23] \text { and }[24]}$ All these factors are associated with an increased risk of therapy-related adverse events and consequently a high frequency of treatment discontinuation, affecting efficacy and long-term outcomes. Therefore, a careful clinical assessment of a patient's physical condition and clinical condition, including the evaluation of organ functions (cardiac, pulmonary, hepatic, gastrointestinal and renal) and the presence of frailty (poor endurance, weakness, low physical activity) and disability (need for help for household activities and personal care), should be routinely performed; this will enable to identify vulnerable elderly patients in whom reduced intensity regimens would increase treatment tolerability, reducing early discontinuation and optimizing efficacy. Patients without risk factors should receive full-dose treatment, whereas for patients with at least one risk factor (age $\geq 75$ years, comorbidities, frailty or disability) a reduced intensity strategy is recommended. ${ }^{18}$

\section{The grey zone and the role of reduced-intensity transplantation}

Patients older than 65 years of age, or younger with serious comorbidities, are generally considered unable to receive high-dose melphalan $\left(200 \mathrm{mg} / \mathrm{m}^{2}\right.$; Mel200) followed by ASCT. However, since chronological age does not always correspond to biological age, patients older than 65 years in excellent clinical condition may be able to tolerate ASCT. For very fit patients, reduced-dose of melphalan $\left(100 \mathrm{mg} / \mathrm{m}^{2}\right.$; Mel100) followed by ASCT can be an option. Two randomized studies comparing reduced-dose of melphalan with the standard MP reported conflicting results. In the first study, conducted in patients aged 65 to 70 years, Mel100 followed by ASCT led to longer median event-free survival (EFS) (28 months vs. 16.4 months; $\mathrm{p}<0.001)$ and OS (58 months vs. 
37.2 months; $\mathrm{p}<0.001$ ) compared with melphalan-prednisone (MP). ${ }^{25}$ The second study compared MP, MP plus thalidomide (MPT) and Mel100 followed by ASCT in patients aged 65-75 years. MPT induced longer PFS and OS in comparison with both MP and Mel100, while no differences were observed between MP and Mel100. ${ }^{26}$

A German ongoing trial is assessing the role of lenalidomide and low-dose dexamethasone (Rd) as induction therapy followed by ASCT in patients 60-75 years of age considered eligible for transplantation. An intermediate dose of melphalan $\left(140 \mathrm{mg} / \mathrm{m}^{2}\right)$ before ASCT has been adopted. Preliminary results confirmed that $\mathrm{Rd}$ is a feasible option in elderly patients, and stem cell mobilization was successful in $97 \%$ of patients. $^{27}$

Bortezomib administered as induction before transplantation was associated with a high CR rate ${ }^{28}$; lenalidomide has shown a great efficacy and lacks neurotoxicity typical of its predecessor thalidomide. ${ }^{29}$ These considerations provided the rationale for a phase II study that evaluated safety and efficacy of these novel agents in combination with a tandem reduced-intensity ASCT (Mel100), in patients aged 65-75 years. ${ }^{30}$ Induction therapy consisted of bortezomib-doxorubicindexamethasone (PAD) for four 21-day cycles, lenalidomide-prednisone (RP) was administered as consolidation for four 28-day cycles, followed by lenalidomide maintenance (R), until progression. This sequential approach led to a progressive improvement of response, CR rate increased from $13 \%$ after PAD induction, to $38 \%$ after Mel100 and ASCT, to $71 \%$ during RP-R consolidation/maintenance. After a median follow-up of 36 months, the 3-year time to progression (TTP), PFS and OS were $73 \%, 66 \%$ and $85 \%$, respectively. PFS was not significantly different in patients younger or older than 70 years $(p=0.16)$, although it was slightly longer in younger patients. The most common grade 3-4 adverse events were thrombocytopenia (17\%), neutropenia $(10 \%)$, peripheral neuropathy $(16 \%)$ and pneumonia $(10 \%)$; lenalidomide given as consolidation/maintenance was well tolerated as it did not cause cumulative or persistent grade 3-4 neutropenia and thrombocytopenia. Different studies showed that the rate of responses induced by bortezomib and lenalidomide rise over the course of treatment, earlier with bortezomib and later with lenalidomide. ${ }^{[10] \text { and }[31]}$

The data above suggest that a sequential approach consisting of induction with effective drug combinations followed by reduced-dose ASCT and subsequent consolidation/maintenance therapy is a valuable therapeutic strategy for very fit elderly patients, or patients younger but not eligible for a high-dose melphalan and ASCT.

\section{Active regimens}

\subsection{IMiDs-based regimens}

In a randomized, phase III trial including newly diagnosed $\mathrm{MM}$ patients ineligible for transplantation, thalidomide combined with high-dose dexamethasone (TD) was compared with MP. ${ }^{32}$ Although TD yielded to a higher overall response rate $(\mathrm{ORR})(68 \%$ vs. $50 \% ; \mathrm{p}=0.002)$ than MP, no differences in terms of median time-to-progression (TTP) (21.2 vs. 29.1 months; $p=0.2)$ and PFS (16.7 vs. 20.7 months; $p=0.1$ ) were noted. In patients younger than 75 years, median OS was shorter with TD (44.6 vs. 57.9 months; $\mathrm{p}=0.14$ ), and this difference was statistically significant in patients older than 75 years receiving TD (19.8 vs. 41.3 months; $p=0.071)$. The incidence of early death, occurred within the first year, with TD twice as high as the one reported with MP ( $28 \%$ vs. $16 \% ; \mathrm{p}=0.014)$; in addition, non-myeloma related deaths were higher in the TD arm, and infection and cardiovascular events were the main causes. These data show that, despite the efficacy benefits observed with TD, this combination is too toxic for elderly patients and the lack of clinical benefit was mainly due to high dose dexamethasone. The choice of different steroids 
(e.g. prednisone) and reduced-dose schedules (e.g. low-dose dexamethasone), may increase treatment tolerability and efficacy.

The combination MP had long been the standard of care for patients unsuitable for high-dose therapy and transplantation. Six randomized trials explored the efficacy of the addition of thalidomide (at different doses, 100-400 mg) to MP in newly diagnosed, transplant ineligible MM patients. In two French studies, IFM 99/06 and IFM 01/01, MPT regimen led not only to a higher

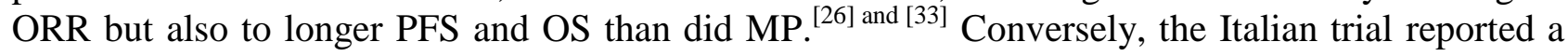
higher ORR and a prolonged PFS in patients treated with thalidomide, but no OS differences were noted between MPT and MP. ${ }^{34}$ Similar data were obtained in the Dutch/Belgian study: MPT prolonged PFS compared with MP, but no OS advantage was seen. ${ }^{35}$ In two other trials performed by the Nordic and Turkish groups, ORR was higher in patients who were given thalidomide, but this advantage did not translate into longer PFS and OS in comparison with those who did not receive thalidomide. ${ }^{[36]}$ and [37]

An efficacy meta-analysis of the six MPT trials including 1685 patients was conducted (Table 2). ${ }^{15}$ Despite the heterogeneity of the trials, both for patient characteristics and thalidomide schedules (dose and duration of treatment), the addition of thalidomide to MP significantly prolonged both PFS and extended OS by $20 \%$ (6.6 months) compared to MP. A safety meta-analysis based on the same trials showed that the incidence of grade 3-4 adverse events was higher (at least $75 \%$ ) during the first six months of treatment for both MPT and MP (Table 3). ${ }^{38}$ Grade 3-4 non-hematologic adverse events occurred more frequently with MPT than MP (39\% vs. 17\%), in particular peripheral neuropathy (6-23\%) and deep-vein-thrombosis (3-12\%), and they were significantly increased in patients with poor performance status. These results showed the superiority of MPT over the old standard of care MP, and MPT is therefore regarded as new standard of care in transplant ineligible patients.

Table 2. Efficacy of selected treatments.

\begin{tabular}{|c|c|c|c|c|c|}
\hline Regimen & Number & Schedule & CR (\%) & PFS/EFS/TTP (\%) & OS (\%) \\
\hline \multicolumn{6}{|l|}{ IMiD-based } \\
\hline $\mathrm{MPT}^{15}$ & 815 & $\begin{array}{l}\text { M: } 0.18 \text { or } 0.25 \mathrm{mg} / \mathrm{kg} \text { day } 1-7 \text { or } 1-4 ; \mathrm{P}: 2 \mathrm{mg} / \mathrm{kg} \text { day } 1-4 ; \mathrm{T}: 100-200 \mathrm{mg} / \mathrm{day} ; \mathrm{M} \\
(0.18 \mathrm{mg}) \mathrm{T}(100 \mathrm{mg}) \text { for six } 28 \text {-day cycles; } \mathrm{M}(0.25 \mathrm{mg}) \mathrm{T}(200 \mathrm{mg}) \text { for twelve } \\
\text { 42-day cycles }\end{array}$ & 14 & 43 at 24 months & 50 at 39 months \\
\hline $\mathrm{CTDa}^{39}$ & 426 & $\begin{array}{l}\text { C: } 500 \mathrm{mg} / \text { week; } \mathrm{T}: 50 \mathrm{mg} \text { for } 4 \text { week increased every } 4 \text { weeks in } 50 \text {-mg increments } \\
\text { to maximum } 200 \mathrm{mg} / \text { day; } \mathrm{D}: 20 \mathrm{mg} / \text { day days } 1-4,15-18 \text { for six to nine } 28 \text {-day cycles }\end{array}$ & 13 & 50 at 13 months & 50 at 33 months \\
\hline $\mathrm{RD}^{42}$ & 223 & R: $25 \mathrm{mg}$ days $1-21$; D: $40 \mathrm{mg}$ days $1-4,9-12,17-20$; for four 28 -day cycles & 5 & 50 at 19 months & 75 at 24 months \\
\hline $\mathrm{Rd}^{42}$ & 222 & R: $25 \mathrm{mg}$ days $1-21 ;$ d: $40 \mathrm{mg}$ days $1,8,15,22$; for four 28 -day cycles & 4 & 50 at 25 months & 76 at 24 months \\
\hline MPR induction & 152 & $\begin{array}{l}\text { M: } 0.18 \mathrm{mg} / \mathrm{kg} \text { days } 1-4 ; \mathrm{P}: 2 \mathrm{mg} / \mathrm{kg} \text { days } 1-4 ; \mathrm{R}: 10 \mathrm{mg} \text { days } 1-21 \text { for nine } \\
\text { 4-week cycles }\end{array}$ & 10 & 50 at 31 months & 70 at 36 months \\
\hline R maintenance ${ }^{14}$ & & $\mathrm{R}: 10 \mathrm{mg}$ days $1-21$ until disease progression & $33 \geq$ VGPR & & \\
\hline \multicolumn{6}{|l|}{ Bortezomib-based } \\
\hline $\mathrm{VMP}^{43}$ & 344 & $\begin{array}{l}\text { V: } 1.3 \mathrm{mg} / \mathrm{m}^{2} \text { days } 1,4,8,11,22,25,29,32 \text { (cycles } 1-4 \text { ), days } 1,8,22,29 \text { (cycles } 5-9 \text { ); } \\
\text { M: } 9 \mathrm{mg} / \mathrm{m}^{2} \text { days } 1-4 ; \mathrm{P}: 60 \mathrm{mg} / \mathrm{m}^{2} \text { days } 1-4 \text { for nine } 42 \text {-day cycles }\end{array}$ & 30 & 50 at 24 months & 68 at 36 months \\
\hline$V_{C D}^{49}$ & 33 & $\begin{array}{l}\mathrm{V}: 1.3 \mathrm{mg} / \mathrm{m}^{2} \text { days } 1,4,8,11 ; \mathrm{C}: 500 \mathrm{mg} / \mathrm{m}^{2} \text { days } 1,8 ; \mathrm{D}: 40 \mathrm{mg} \text { days } 1,8,15 \text { for eight } \\
\text { 21-day cycles }\end{array}$ & 22 & 93 at 12 months & 100 at 12 months \\
\hline $\mathrm{VD}^{45}$ & 168 & $\begin{array}{l}\text { V: } 1.3 \mathrm{mg} / \mathrm{m}^{2} \text { days } 1,4,8,11 ; \mathrm{D}: 20 \mathrm{mg} \text { days } 1,2,4,5,8,9,11,12 \text { (cycle } 1-4 \text { ), days } 1,2,4,5 \\
\text { (cycle } 5-8 \text { ) for } 821 \text {-day cycles }\end{array}$ & $33 \mathrm{CR} / \mathrm{nCR}$ & 50 at 14 months & 87 at 12 months \\
\hline \multicolumn{6}{|l|}{ IMiD plus bortezomib } \\
\hline VMPT induction & 254 & $\begin{array}{l}\mathrm{V}: 1.3 \mathrm{mg} / \mathrm{m}^{2} \text { days } 1,8,15,22 ; \mathrm{M}: 9 \mathrm{mg} / \mathrm{m}^{2} \text { days } 1-4 ; \mathrm{P}: 60 \mathrm{mg} / \mathrm{m}^{2} \text { days } 1-4 ; \mathrm{T} \text { : } \\
50 \mathrm{mg} / \text { day for nine } 35 \text {-day cycles }\end{array}$ & 38 & 56 at 36 months & 89 at 36 months \\
\hline VT maintenance ${ }^{10}$ & & $\mathrm{~V}: 1.3 \mathrm{mg} / \mathrm{m}^{2}$ every 14 days; $\mathrm{T}: 50 \mathrm{mg} / \mathrm{day}$ for 2 years & 42 & & \\
\hline VRD $^{48}$ & 35 & $\begin{array}{l}\mathrm{V}: 1.3 \mathrm{mg} / \mathrm{m}^{2} \text { days } 1,4,8,11 ; \mathrm{R}: 25 \mathrm{mg} \text { days } 1-14 ; \mathrm{D}: 20 \mathrm{mg} \text { days } 1,2,4,5,8,9,11,12 \\
\text { (or days } 1,8,15 \text { ) for eight } 28 \text {-day cycles }\end{array}$ & 37 & 75 at 18 months & 97 at 18 months \\
\hline
\end{tabular}

MPT, melphalan-prednisone-thalidomide; CTDa, attenuated regimen of cyclophosphamide-thalidomide-dexamethasone; RD, lenalidomide plus high-dose dexamethasone; Rd, lenalidomide plus low-dose dexamethasone; MPR, melphalan-prednisone-lenalidomide; R, lenalidomide; VMP, bortezomib-melphalan-prednisone; VCD, bortezomib-cyclophosphamidedexamethasone; VD, bortezomib-dexamethasone; VMPT, bortezomib-melphalan-prednisone-thalidomide; VT, bortezomib-thalidomide; VRD, bortezomib-lenalidomide-dexamethasone; CR, complete response; nCR, near complete response; VGPR, very good partial response; PFS, progression-free survival; EFS, event-free survival; TTP, time to progression; OS, overall survival.

$\checkmark$ Alternative VMP schedule: $\mathrm{V} 1.3 \mathrm{mg} / \mathrm{m}^{2}$ days $1,8,15,22 ; \mathrm{M} 9 \mathrm{mg} / \mathrm{m}^{2} \mathrm{~d} 1-4 ; \mathrm{P} 50 \mathrm{mg} / \mathrm{m}^{2} \mathrm{~d} 1-4$. 
Table 3. Safety of selected treatments.

\begin{tabular}{|c|c|c|c|c|c|c|}
\hline \multirow[t]{2}{*}{ Regimen } & \multirow{2}{*}{$\begin{array}{l}\text { Discontinuation } \\
\text { due to AEs (\%) }\end{array}$} & \multicolumn{2}{|c|}{ Grade 3-4 hematologic AEs } & \multicolumn{3}{|c|}{ Grade 3-4 non-hematologic AEs } \\
\hline & & Neutropenia (\%) & Thrombocytopenia (\%) & PN (\%) & $\operatorname{VTE}(\%)$ & Infection (\%) \\
\hline \multicolumn{7}{|l|}{ IMiD-based } \\
\hline $\mathrm{MPT}^{15}$ & $16-45$ & $16-48$ & $3-14$ & $1-6$ & $2-6$ & $4-20$ \\
\hline $\mathrm{CTDa}^{39}$ & NA & 15 & NA & $2.6 / 4^{\mathrm{b}}$ & 0 & 13 \\
\hline $\mathrm{Rd}^{42}$ & 19 & 20 & 5 & 2 & 12 & 9 \\
\hline MPR induction & $16^{\mathrm{a}}$ & $35^{\mathrm{a}}$ & $11^{\mathrm{a}}$ & $0^{\mathrm{a}}$ & $3^{a}$ & $11^{\mathrm{a}}$ \\
\hline R maintenance ${ }^{14}$ & $9^{\mathrm{a}}$ & $7^{\mathrm{a}}$ & $6^{\mathrm{a}}$ & $0^{\mathrm{a}}$ & 2 & $3^{\mathrm{a}}$ \\
\hline \multicolumn{7}{|l|}{ Bortezomib-based } \\
\hline $\mathrm{VMP}^{43}$ & 15 & 40 & 37 & 13 & 1 & 10 \\
\hline $\mathrm{VCD}^{49}$ & 9 & 13 & 25 & 7 & 7 & NA \\
\hline $\mathrm{VD}^{45}$ & 24 & NA & NA & 23 & 8 & 10 \\
\hline \multicolumn{7}{|l|}{ IMiD plus bortezomib } \\
\hline VMPT induction & 23 & 38 & 22 & 8 & 5 & 13 \\
\hline VT maintenance ${ }^{10}$ & & 3 & $<1$ & 5 & 2 & 1 \\
\hline VRD $^{48}$ & 19 & 9 & 6 & 7.5 & 4.5 & 2 \\
\hline
\end{tabular}

A phase III trial assessed the role of thalidomide in combination with different alkylating agent and steroid than those commonly used, respectively cyclophosphamide and dexamethasone, with an attenuated schedule (CTDa). ${ }^{39}$ In this trial, 849 newly diagnosed MM elderly patients were randomly allocated to CTDa or MP. Of note, $75 \%$ of patients had an advanced stage disease (ISS II/III). CTDa resulted in higher ORR (63.8\% vs. $32.6 \mathrm{p}<0.0001 \%)$, very good partial response (VGPR; $16.9 \%$ vs. $1.7 \%)$ and CR (13.1\% vs. 2.4\%) than MP. Despite a deeper response, no differences were noted in median PFS (13 months vs. 12.4 months, $\mathrm{p}=0.1$ ) and OS (33.2 months vs. 30.6 months, $\mathrm{p}=0.24$ ) between patients treated with CTDa or MP. CTDa induced a higher rate of grade 3-4 adverse events, especially peripheral neuropathy, constipation and DVT. However, patients with favorable FISH benefited more from CTDa and showed an improved OS.

Lenalidomide is a potent IMiD derived from thalidomide; this compound showed to be safe and effective in relapsed/refractory MM patients, as well as in newly diagnose MM patients. ${ }^{[40] \text { and }[41]}$ In a phase III trial, lenalidomide plus high-dose dexamethasone (RD) was compared with lenalidomide plus low-dose dexamethasone (Rd) in newly diagnosed MM patients, both eligible and ineligible for ASCT. ${ }^{42}$ Despite a higher ORR with RD $(79 \%$ vs. $68.3 \%, p=0.008)$, patients treated with Rd had a significantly longer 1-year OS (87\% vs. $96 \%, \mathrm{p}<0.001)$. The survival benefit associated with $\mathrm{Rd}$ was particularly evident in patients older than 65 years of age (1-year OS: $83 \%$ with RD vs. 94\% with $\mathrm{Rd}$ ). In a landmark analysis, 3-year OS for patients who continued treatment until progression or intolerance was $79 \%$. RD was associated with a worse toxicity profile, with a higher incidence of grade 3-4 adverse events, particularly DVT (26\% vs. $12 \%)$ and infections (16\% vs. 9\%). Early deaths were also significantly higher with the high-dose dexamethasone (5\% vs. $0.4 \%$, $\mathrm{p}<0.003)$. Consequently, discontinuation rate was higher with RD than with $\mathrm{Rd}(27 \%$ vs. 19\%). In a subgroup analysis including patients older than 70 years of age, the 3 -year OS was $61 \%$ with RD and $73 \%$ with $\mathrm{Rd}$, and the incidence of grade 3-4 non-hematologic adverse events was $78 \%$ and $59 \%$, respectively. Based on these results, Rd regimen can be considered a valid therapeutic option for elderly newly diagnosed MM, and low-dose dexamethasone (40 $\mathrm{mg}$ weekly) should be preferred in this setting. 


\subsection{Bortezomib-based regimens}

The international phase III VISTA trial assessed the role of bortezomib in combination with melphalan and prednisone (VMP), with the standard MP. ${ }^{43}$ VMP led to higher ORR and CR rate, which translated into longer TTP (24 months vs. 16.6 months; $p<0.001)$ and OS (56.4 vs. 43.1; $\mathrm{p}=0.0004$ ), with a $31 \%$ reduced risk of death. These results were confirmed in different subgroups of patients, included patients older than 75 years, but not in those with high-risk cytogenetic profile. VMP was more toxic than MP, with grade 3-4 adverse event rate of $91 \%$ and a discontinuation rate of 34\%; the most frequent grade 3-4 toxicities were neutropenia (40\%), thrombocytopenia (37\%), peripheral neuropathy $(17 \%)$ and infections $(10 \%)$. When bortezomib schedule was changed from twice-weekly (cycles 1 to 4) to once-weekly (cycles 5 to 8), the rate of adverse events decreased in the VMP group, with no negative impact on outcome. Therefore, VMP today is considered one of the standard approaches for elderly MM patients, and the once-weekly bortezomib schedule is a valid alternative strategy. ${ }^{[10]}$ and [44]

In another phase III trial including newly-diagnosed elderly MM patients, VMP was compared with bortezomib-dexamethasone (VD) and bortezomib-thalidomide-dexamethasone (VTD). ${ }^{45}$ In this study median age was $72-74.5$ years, more than $2 / 3$ of patients had an advanced disease (ISS stage II/III) and approximately $50 \%$ of them presented with a Charlson comorbidity index $\geq 1$. After a median follow-up of 21.8 months, the ORR response rate was equivalent in the three regimens (69\%-80\%), and no differences in PFS and OS were noted. Grade 3-4 adverse events and discontinuation rate were higher in patients treated with VTD. These data support the use of lower doses of standard regimens or a 2-drug combination, rather than a more intense treatment, in very elderly patients, or in younger patients with heart, lung, liver, or renal dysfunctions, or in those needing help for household care and personal care.

Promising results came from a phase II study combining bortezomib with cyclophosphamide and dexamethasone (VCD) in newly diagnosed MM patients, both eligible and not eligible for

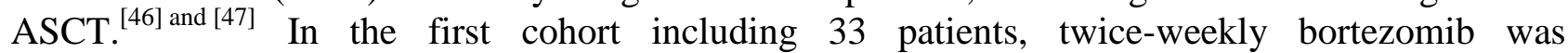
administered; in the second cohort including other 30 patients, once-weekly bortezomib was given. After 4 cycles of induction, the ORR was $90 \%$ and the $\mathrm{CR} / \mathrm{near} \mathrm{Cr}(\mathrm{nCr})$ rate was $41 \%$, with no differences between the once-weekly and the twice-weekly schedule in terms of response. However, the rate of grade 3-4 adverse events was lower with the once-weekly group.

\subsection{Bortezomib plus IMiDs-based regimens}

The proteasome inhibitor bortezomib has been combined with IMiDs, thalidomide and lenalidomide, as induction therapy for newly diagnosed MM patients. In the Spanish PETHEMA trial, 260 patients older than 65 years or otherwise ineligible for ASCT, were randomized to receive 6 cycles of either bortezomib-thalidomide-prednisone (VTP) or VMP induction; a gentler approach with once-weekly bortezomib was used from cycle 2 of both regimens. ${ }^{44}$ Both VTP and VMP led to high ORR rate $(81 \%$ and $80 \%$, respectively) and CR rate $(28 \%$ and $20 \%$, respectively). VTP regimen was more toxic than VMP, inducing a higher rate of serious adverse events, particularly cardiac events, $(31 \%$ vs. $15 \% ; p=0.01)$ and discontinuation rate $(17 \%$ vs. $12 \% ; p=0.03)$. VMP was associated with a higher rate of grade 3-4 hematologic adverse events compared to VTP, in particular neutropenia (39\% vs. $22 \% ; \mathrm{p}=0.008)$ and thrombocytopenia $(27 \%$ vs. $12 \% ; \mathrm{p}<0.001)$. The once-weekly schedule of bortezomib adopted after the first cycle, reduced the rate of grade 3-4 peripheral neuropathy and gastrointestinal symptoms compared with the twice-weekly schedule, without affecting efficacy. ${ }^{43}$ Therefore, VMP with a once-weekly schedule of bortezomib should be preferred to VTP as induction for elderly MM patients. 
A phase I/II trial evaluated the safety and efficacy of the combination of bortezomib-lenalidomidedexamethasone (VRD) in both young and elderly newly diagnosed MM patients. ${ }^{48}$ The first phase of this trial established the maximum planned dose of bortezomib $\left(1.3 \mathrm{mg} / \mathrm{m}^{2}\right)$, lenalidomide (25 mg) and dexamethasone (20 mg cycle $1-4 ; 10 \mathrm{mg}$ cycle 5-8). Patients who did not proceed to ASCT, received eight 3-week cycles of VRD. This regimen proved to be highly effective, leading to a PR rate of $100 \%$ and a $\mathrm{CR} / \mathrm{nCR}$ rate of $37 \%$. VRD was also well tolerated: the most frequent grade 3-4 adverse events were neutropenia (9\%) and thrombocytopenia (6\%); in addition, no grade 4 peripheral neuropathy was reported. After 18 months from start of treatment, PFS was $75 \%$ and OS was $97 \%$.

A subsequent phase II trial explored the role of bortezomib-cyclophosphamide-dexamethasone (VCD), compared to VRD and VRD plus cyclophosphamide (VDCR) in both transplant eligible and ineligible newly diagnosed MM patients. ${ }^{49}$ All regimens were effective: ORR and CR rate were $75 \%$ and $22 \%$ with VCD, $85 \%$ and $24 \%$ with VRD, and $88 \%$ and $25 \%$ with VDCR. These responses translated into similar 1-year PFS (97\%, 68\%, 83\%, respectively) and 1-year OS (100\%, $100 \%, 92 \%$, respectively). The 4-drug regimen led to higher rate of grade 3-4 adverse events, particularly neutropenia, and discontinuation rate, and its efficacy is thus comparable to the 3-drug regimens.

\section{Continuous treatment}

Despite the improvement reported with novel agents containing therapies, residual disease is always present. Therefore, a continuous treatment to keep residual disease under control is an effective strategy. Recently, the international MM015 phase III study assessed the role of lenalidomide given as maintenance. ${ }^{14}$ Four-hundred and fifty-nine patients were randomized to receive induction therapy consisting of nine 4-week cycles of MPR, followed by either lenalidomide maintenance or placebo, or standard MP. Lenalidomide was administered at the dose of $10 \mathrm{mg}$ daily, both at induction and during maintenance. The median age at enrollment was 71 years and half of patients had advanced disease (ISS III). The ORR was higher with MPR-R and MPR compared with MP (77\%, 68\%, 50\%, respectively). MPR-R significantly improved median PFS in comparison with MPR and MP (31 months vs. 14 months vs. 13 months; $p<0.001$ ). Of note, MPR-R reduced the risk of progression by $51 \%$ and $60 \%$ compared with MPR and MP, respectively. This advantage was more evident in patients younger than 75 years, in whom MPR-R significantly improved PFS compared to MPR and MP. In a landmark analysis from start of maintenance, lenalidomide maintenance significantly prolonged PFS as compared to placebo, regardless of age (26 months with MPR-R vs. 7 months with MPR-placebo, $\mathrm{p}<0.001$ ), with a $66 \%$ reduced risk of progression. The most frequent hematologic grade 4 adverse events were neutropenia (35\% with MPR-R, 32\% with MPR, $8 \%$ with MP), and thrombocytopenia (11\%, 12\%, and 4\%, respectively). Infections were the most frequent non-hematologic grade 3 adverse events (9\% with MPR-R, 13\% with MPR, 7\% with MP), while the rate of deep vein thrombosis (DVT) was low (1\%, 4\%, and $1 \%$, respectively) because thromboprophylaxis with aspirin was used. Maintenance therapy was well tolerated, as the rate of new or worsened grade 3-4 adverse events lowered (0 to 6\%).

The role of continuous treatment with bortezomib has been assessed in two different trials. In the Spanish PETHEMA trial, patients were randomized to receive bortezomib maintenance (standard schedule day 1, 4, 8, 11administerd every 3 months) with either thalidomide (VT) or prednisone (VP), after VTP or VMP induction. ${ }^{17}$ After 38 months from the initiation of maintenance, both VT and VP increased the CR rate achieved after induction (up to $46 \%$ with VT and up to $39 \%$ with VP) without significantly adding to toxicity (grade 3-4 neutropenia: $1 \%$ in the VT arm vs. $0 \%$ in the VP arm; grade 3-4 peripheral neuropathy: $9 \%$ vs. 3\%, respectively). PFS was longer with VT 
compared with VP (39 months vs. 32 months, $\mathrm{p}=0.1$ ), 5-years OS was slightly prolonged with VT (69\% vs. $50 \%, \mathrm{p}=0.1)$.

In the Italian study, bortezomib was tested as maintenance in combination with thalidomide (VT), after nine 6-week cycles of VMPT induction, and compared with nine 6-week cycles of VMP induction followed by placebo. During maintenance, bortezomib was given at the dose of $1.3 \mathrm{mg} / \mathrm{m}^{2}$, every 14 days for up to two years or until disease progression. ${ }^{[10]}{ }^{\text {and }}{ }^{[13]}$ After 47 months of follow-up, 5-year OS was $59.3 \%$ for VMPT-VT and $45.9 \%$ for VMP, with a $26 \%$ reduced risk of death in favor of VMPT-VT. The survival benefit associated with VMPT-VT was more evident in patients younger than 75 years $(67.8 \%$ vs. $49.4 \% ; \mathrm{p}=0.001)$ and in patients who achieved CR after induction $(81.4 \%$ vs. $48.2 \%$; $\mathrm{p}=0.006)$. On the contrary, no advantage with VMPT-VT was observed in patients older than 75 years in comparison with VMP. In a pre-specified landmark analysis at the start of maintenance, 4-year OS was $64.6 \%$ in the VMPT-VT arm and $49.7 \%$ in the VMP arm, with a $33 \%$ reduced risk of death in favor of VMPT-VT. VT maintenance was well tolerated: the incidence of grade 3-4 adverse events was low, with peripheral neuropathy rate of 7\%. No OS differences were noted at relapse, showing that VMPT-VT did not negatively impact on efficacy of salvage therapy. When bortezomib schedule was changed from twice- to onceweekly administration, the incidence of non-hematologic grade 3-4 adverse events decreased from $51 \%$ to $36 \%$ ( $p=0.003$ ), particularly peripheral neuropathy (from $16 \%$ to $3 \%, p<0.001)$. ${ }^{[10] \text { and [50] }}$ This modification did not affect efficacy, as the cumulative delivered dose of bortezomib was similar. ${ }^{50}$ Therefore, VMPT-VT with once-weekly bortezomib seems a valid alternative for elderly patients, especially for those 65-75 years of age.

Beside the weekly schedule, the recent use of subcutaneous administration rather than the intravenous administration showed to be a feasible and equally effective option. ${ }^{51}$ Therefore, subcutaneous bortezomib may be considered for prolonged treatment.

These data confirm that a sequential approach including maintenance with either lenalidomide alone or bortezomib in combination with thalidomide is safe and effective in elderly patients. This strategy prolongs PFS with an acceptable toxicity rate, and also extends OS.

\section{Treatment options for fit and unfit patients}

As previously reported, in presence of $\geq 1$ risk factor (age $\geq 75$ years, presence of comorbidities, frailty or disability), dose reductions are recommended (Table 4). In case of grade 3-4 adverse events occurring during treatment, therapy should be withheld until the toxicity resolves; therapy could then be restarted at the beginning of the next cycle at a lower dose level. ${ }^{1}$ Thalidomide may be reduced from $200 \mathrm{mg}$ to $100 \mathrm{mg}$ or even $50 \mathrm{mg}$ per day; lenalidomide from $25 \mathrm{mg}$ to $15-10 \mathrm{mg}$ on days 1-21; once weekly administration of bortezomib at the dose of $1.3 \mathrm{mg} / \mathrm{m}^{2}$, or even $1.0 \mathrm{mg} / \mathrm{m}^{2}$, instead of the standard twice-weekly, should be considered; the dose of melphalan may be decreased from $0.25 \mathrm{mg}$ to $0.18 \mathrm{mg}$ or even $0.13 \mathrm{mg}$ per kilogram of body weight on days $1-4$; low-dose schedule dexamethasone (40 mg daily on days $1,8,15,22)$ should be preferred to the highdose schedule, and may be further decreased to $20 \mathrm{mg}$ weekly. 
Table 4. Suggested dose adjustments.

\begin{tabular}{llll}
\hline Drug & Initial/standard dose & Reduced dose & Further reduction if needed \\
\hline Dexamethasone & $40 \mathrm{mg} / \mathrm{d}$ & $20 \mathrm{mg} / \mathrm{d}$ & $10 \mathrm{mg} / \mathrm{d}$ \\
& days $1,8,15,22$ every 4 weeks & days $1,8,15,22$ every 4 weeks & days $1,8,15,22$ every 4 weeks \\
Melphalan & $0.25 \mathrm{mg} / \mathrm{kg}$ or $9 \mathrm{mg} / \mathrm{m}^{2}$ & $0.18 \mathrm{mg} / \mathrm{kg}$ or $7.5 \mathrm{mg} / \mathrm{m}^{2}$ & $0.13 \mathrm{mg} / \mathrm{kg}$ or $5 \mathrm{mg} / \mathrm{m}^{2}$ \\
& $\mathrm{~d} 1-4 \mathrm{every} 4-6 \mathrm{wks}$ & $\mathrm{d} 1-4 \mathrm{every} 4-6 \mathrm{wks}$ & $50 \mathrm{mg}$ qod \\
Thalidomide & $100 \mathrm{mg} / \mathrm{d}$ & $50 \mathrm{mg} / \mathrm{d}$ & $10 \mathrm{mg} / \mathrm{d}$ \\
Lenalidomide & $25 \mathrm{mg} / \mathrm{d}$ & $15 \mathrm{mg} / \mathrm{d}$ & days $1-21$ every 4 weeks \\
(plus dexamethasone) & days $1-21$ every 4 weeks & days $1-21$ every 4 weeks & $5 \mathrm{mg} \mathrm{qod}$ \\
Lenalidomide & $10 \mathrm{mg} / \mathrm{d}$ & $5 \mathrm{mg} / \mathrm{d}$ & days $1-21$ every 4 weeks \\
(plus melphalan-prednisone) & days $1-21$ every 4 weeks & days $1-21$ every 4 wks & $1.0 \mathrm{mg} / \mathrm{m}^{2}$ once weekly \\
Bortezomib & $1.3 \mathrm{mg} / \mathrm{m}^{2}$ twice weekly & $1.3 \mathrm{mg} / \mathrm{m}^{2}$ once weekly & days $1,8,15,22$ every 5 weeks \\
\hline
\end{tabular}

The standard of care for elderly patients consists of a 3-drug regimen (VMP, VCD or VRD). In patients aged 65-75 years, the 4-drug regimen VMPT can be adopted, as it significantly increased the CR rate compared with VMP $(38 \%$ vs. $24 \%$; p < 0.001$) .{ }^{10}$ If an oral treatment is required, IMiD-containing regimens are recommended, such as the standard MPT or Rd. Recently, maintenance therapy with lenalidomide or VT improved PFS, but longer follow-up is needed to detect an OS advantage. Lenalidomide maintenance proved to be highly effective, regardless of age, and is a feasible option, especially for its oral administration. ${ }^{14}$ VT maintenance, after bortezomibbased induction, is a valuable option for elderly patients, and the once-weekly administration has improved its tolerability. ${ }^{10}$

Unfit patients should receive a gentler approach associated with a low rate of adverse events and treatment discontinuation. In this setting, 2-drug combinations such as VD and $\mathrm{Rd}$ are recommended. VD proved to be less toxic and equally effective as VMP and VTD in an elderly and frail population. ${ }^{45}$ Similarly, Rd was better tolerated than RD and proved to be even more effective, owing to the low-dose schedule of dexamethasone, both in young and elderly patients. ${ }^{42}$

A phase II trial tested the role of lenalidomide-prednisone (RP) induction, followed by consolidation with MPR and subsequent RP maintenance therapy in elderly patients. Median age was 75 years and $60 \%$ had at least 1 comorbidity. ${ }^{52}$ This strategy led to a significant reduction in the rate of grade 4 hematologic adverse events associated with MPR. These results suggest that an initial gentler approach with a 2-drug regimen as induction, when toxicity rate is higher, followed by a more intense treatment with a 3 -drug combination is an effective option for vulnerable elderly patients.

\section{Treatment strategy at relapse}

Patients with relapsed $\mathrm{MM}$ experience disease progression after achieving maximal response to induction treatment, whereas refractory patients either do not respond to therapy or progress within 60 days from last treatment. ${ }^{53}$ The choice of therapy at relapse should be based on quality and duration of response obtained with the previous therapy. A profound cytoreduction followed by a sustained response (longer than 24 months at diagnosis and 6-12 months at relapse) suggests to retreat with the same combination previously administered; in presence of short-term remission duration (less than 6 months) or progression during initial therapy, a different treatment regimen should be adopted. ${ }^{54}$ In presence of a biochemical relapse, that is $\geq 25 \%$ increase in the serum or urine protein and $\geq 0.5 \mathrm{mg} / \mathrm{dL}$ without symptoms, early treatment may keep the recurrence of the disease under control and delay clinical relapse. 
Two-drug regimens consisting of dexamethasone plus bortezomib ${ }^{[55]}$ and [56] or lenalidomide $^{[40] \text { and [57] }}$ are the treatments of choice for relapsed patients. In the phase III APEX trial conducted in patients relapsed after at least 1 prior therapy, bortezomib alone showed to be superior to dexamethasone in terms of ORR ( $38 \%$ vs. $18 \%$; $<$ < 0.001$)$, TTP (6.2 vs. 3.5 months; $p<0.001)$ and 1 -year OS $(80 \%$ vs. $60 \% ; p=0.003) .{ }^{58}$ An updated analysis showed an increase in ORR with bortezomib $(43 \%)$ and confirmed the survival advantage with bortezomib over dexamethasone (29.8 vs. 23.2 months; $\mathrm{p}=0.27$ ), although $60 \%$ of patients in the dexamethasone arm were allowed to receive bortezomib. ${ }^{59}$

Two phase III randomized trials, MM09 and MM010, enrolled relapsed/refractory patients after 1 to 3 lines of prior therapy, and showed the superiority of RD over dexamethasone alone. ${ }^{[29] \text { and }[40]} \mathrm{RD}$ resulted in higher ORR (60\% vs. 20-24\%) and longer median TTP (11 vs. 4.7 months) and median OS (29.6 vs. 20.6 months) compared with dexamethasone. These results led to the approval of lenalidomide for relapsed/refractory MM patients both in USA and Europe.

When the treatment proves to be ineffective, a third drug (melphalan, cyclophosphamide or doxorubicin) may be added to enhance efficacy. In addition, bortezomib-based regimens should be preferred in relapsed patients with renal failure or previous deep-vein thrombosis. ${ }^{60}$ Patients previously treated with a thalidomide-containing regimen benefit from treatment with lenalidomide, although efficacy and survival may be lower ${ }^{61}$ Because of the lack of neurotoxicity, lenalidomide is suggested in case of concomitant peripheral neuropathy. ${ }^{60}$

The second generation proteasome inhibitor carfilzomib has shown a remarkable activity in relapsed/refractory MM patients, with a low rate of hematological AEs and the absence of neurotoxicity. ${ }^{62}$ The pivotal PX-171-003-A0 and PX-171-003-A1 studies tested single-agent carfilzomib in MM patients previously exposed to bortezomib and at least one IMiD. ${ }^{[63] \text { and [64] }}{ }^{\text {The }}$ ORR was $24 \%$ and the duration of therapy was 7.4 months. These data led to the FDA approval of carfilzomib as a single agent in relapsed/refractory MM patients after $\geq 2$ lines of previous therapy, including bortezomib and one IMiDs. Carfilzomib was also tested in less heavily pre-treated and bortezomib-naïve relapsed/refractory MM, showing ORR of $42-52 \% .{ }^{65}$ Recently, different doses of carfilzomib, lenalidomide and low-dose dexamethasone (CRd) were investigated in the relapse setting, resulting in an ORR of $75 \%$ at the highest dosage. ${ }^{66}$ The ongoing, phase III, randomized ASPIRE trial, is assessing the role of CRd in comparison with $\mathrm{Rd}$ in relapse/refractory MM patients.

Pomalidomide, a new immunomodulatory drug, has recently shown high efficacy in patient's refractory to bortezomib and IMiDs. Clinical trials evaluating the efficacy of the dexamethasone and pomalidomide (dose, 2-4 mg) in patients relapsed and/or refractory to lenalidomide, bortezomib or both, reported a PR rate of $32-35 \%$ and a median PFS of 4.6-6.3 months. The addition of a third drug (cyclophosphamide) to the combination of prednisone and pomalidomide (PCP) increased at least PR rate (54\%) and prolonged PFS (52\% at 1 year). ${ }^{67}$ In a heavily pretreated population (median of 5 lines of previous therapy), the addition of clarithromycin to pomalidomide-dexamethasone induced a PR rate of $32 \%$ and a median PFS of 8.2 months. ${ }^{68}$

A new generation of novel agents is currently under evaluation in relapsed/refractory MM patients: anti-CS1 monoclonal antibody (elotuzumab plus lenalidomide- or bortezomib-dexamethasone), oral proteasome inhibitor MLN9708, anti-CD138 antibody BT062 and histone deacetylase inhibitors vorinostat and panobinostat. Future trials will validate the role of these agents.

\section{Management of adverse events}


Prompt action with appropriate dose reductions is needed to manage adverse events, more frequent in elderly patients.

\subsection{Hematologic toxicity}

\subsubsection{Anemia}

Anemia, typically due to bone marrow infiltration of MM cells, occurs in approximately two-thirds of newly-diagnosed MM patients. ${ }^{69}$ Erythropoiesis-stimulating agents (ESAs) are recommended for patients receiving chemotherapy to improve quality of life and reduce the risk of transfusion, particularly in patients with impaired renal function and those with low hemoglobin levels despite responding to therapy. ESAs should be started when hemoglobin level drops below $10 \mathrm{~g} / \mathrm{dl}$; in patients with impaired cardiac function or difficulty in performing daily-life activity, treatment can be started earlier. Hemoglobin level should be approximately $11-12 \mathrm{~g} / \mathrm{dl}$, as higher levels may increase the risk of cardiac events; when ESAs are administered in patients treated with multi-drug regimens containing thalidomide or lenalidomide, the risk of thromboembolic events may increase. $^{70}$

\subsubsection{Neutropenia}

Neutropenia increases the risk of severe infection, a major cause of death in MM patients, and is generally related to chemotherapy. The risk of severe neutropenia (grade 3-4) during treatment is related to patient characteristics, baseline absolute neutrophil count (ANC), disease stage and type of chemotherapy administered (3-drug regimens including lenalidomide plus alkylators or doxorubicin are at high risk). ${ }^{71}$ Granulocyte-colony stimulating factor (G-CSF) can be used to manage severe neutropenia, both as primary prophylaxis or reactive treatment, thus allowing patients to stay on therapy for a longer period. Patients receiving high-risk therapies (expected grade 3-4 neutropenia rate $>50 \%$ ) and those receiving intermediate- or low-risk regimens (expected grade 3-4 neutropenia rate $<50 \%$ ) with additional risk factors, should be given G-CSF as primary prophylaxis. In patients receiving intermediate- or low-risk regimens with no other risk factor, G-CSF should be used only after occurrence of grade 3/4 neutropenia. If ANC rises to $>1000$ cells $/ \mathrm{mL}$, therapy can be resumed and no dose modifications are needed. In case of persisting severe neutropenia despite G-CSF, therapy should be delayed until ANC recovery (> 1000 cells $/ \mathrm{mL}$ ) and then restarted with appropriate dose reductions. ${ }^{71}$

\subsubsection{Thrombocytopenia}

Alkylating and novel agents, especially bortezomib and lenalidomide, are frequently associated with thrombocytopenia. ${ }^{72}$ When platelet count falls below $<25,000 / \mathrm{mm}^{3}$ (grade 4 thrombocytopenia) therapy should be withheld until thrombocytopenia resolves to at least grade 2 (platelet count $\geq 50,000 / \mathrm{mm}^{3}$ ). Therapy could be then reintroduced with appropriate dose reductions of myelotoxic drugs.

\subsection{Non-hematologic toxicity}

\subsubsection{Peripheral neuropathy}

Peripheral neuropathy (PN) is a common side effect observed in patients receiving thalidomide or bortezomib. It may frequently present as sensory neuropathy, neuropathic pain or, less frequently, as motor or autonomic neuropathy. Since PN is associated with the duration of drug exposure and no effective prophylactic measures are currently available to prevent it, dose reductions and 
temporary discontinuation are fundamental. ${ }^{73}$ Patients must be advised about signs and symptoms related to PN in order to promptly recognize and report them to physician. Different strategies have been recently assessed to decrease the rate of PN related to bortezomib. Phase III trials reported that the once-weekly schedule of bortezomib significantly decreased the rate of all grade PN and grade 3-4 PN compared to the twice-weekly schedule, without affecting efficacy. ${ }^{[10],[13] \text { and }[44]}$ Recently, a phase III study showed that the subcutaneous administration of bortezomib significantly reduced the rate of all grades $\mathrm{PN}$ and grade $\geq 3 \mathrm{PN}$ in comparison with the intravenous administration, without negatively affecting responses and survival. ${ }^{51}$ When grade 1 PN without pain occurs, bortezomib dose should be decreased by one dose level or the schedule changed from twice- to once-weekly administration; if PN occurs during once-weekly bortezomib, the dose should be reduced by one dose level. In case of grade 2 PN, bortezomib dose should be decreased or changed to once-weekly administration; for patients receiving once-weekly bortezomib, dose reduction or temporary interruption should be considered. If neuropathy resolves to at least grade 1, bortezomib can be restarted at reduced dose and administered once-weekly. If grade 3-4 PN occurs treatment should be discontinued. ${ }^{74}$ For patients receiving thalidomide, when grade 2 PN occurs, halving thalidomide dose is an effective strategy; when grade $\geq 3$ PN occurs, treatment with thalidomide should be discontinued and may be resumed if PN improves to grade 1 after appropriate dose reduction. ${ }^{75}$

\subsubsection{Venous thromboembolism}

Patients with MM have an increased risk of venous thromboembolism (VTE). Patient-related risks (age, obesity, inherited thrombophilia, history of VTE, immobilization, surgery, central venous catheter, comorbidity, ESAs treatment), myeloma-related risks (myeloma itself and hyperviscosity) and the type of chemotherapy performed should guide the choice of the most appropriate antithrombotic prophylaxis. Thalidomide ${ }^{76}$ and lenalidomide ${ }^{77}$ alone do not increase the risk of VTE. However, the addition of high-dose dexamethasone or doxorubicin to thalidomide or lenalidomide, or their administration in multi-drug chemotherapy, significantly increased the VTE

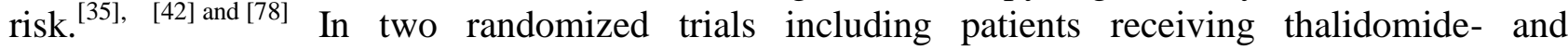
lenalidomide-based regimens, aspirin and low-molecular weight heparin (LMWH) showed equal efficacy in reducing VTE. In low-risk patients (none or only one risk factor) receiving thalidomide or lenalidomide, prophylaxis with aspirin is recommended; in high-risk patients ( $\geq 2$ risk factors) or in those treated with high-dose dexamethasone, doxorubicin or multi-drug chemotherapy, LMWH or full-dose warfarin should be used. ${ }^{78}$

\subsubsection{Renal failure}

Renal failure occurs in 20-40\% of MM patients at diagnosis, due to damages related to free-light chains and concomitant factors, such as hyperuricaemia, hypercalcemia, dehydration and infections; nephrotoxic drugs may further impair renal function. Early intervention consists of reducing the load of free-light chains, removing precipitating factors. High-dose dexamethasone is able to rapidly reduce the load of light chains and to improve renal function. ${ }^{79}$ Pharmacokinetic of bortezomib and thalidomide are not affected by renal dysfunction. Bortezomib is well tolerated and highly active in patients with renal failure, being able to reverse renal impairment. ${ }^{80}$ Bortezomib plus dexamethasone is the treatment of choice in this setting. ${ }^{81}$ Lenalidomide is primarily excreted by kidneys, hence its dose must be adjusted based on creatinine clearance (CLcr). ${ }^{82}$ When CLcr level is between $30-60 \mathrm{~mL} / \mathrm{min}$, lenalidomide recommended dose is $10 \mathrm{mg}$ per day; if CLcr level is below $30 \mathrm{~mL} / \mathrm{min}$, lenalidomide should be given at the dose of $15 \mathrm{mg}$ every other day in patients not requiring dialysis or at the dose of $5 \mathrm{mg}$ on the day of dialysis in patients under dialysis. Hematologic function should be closely monitored. ${ }^{83}$

\subsubsection{Infections}


Bone marrow infiltration by MM cells and myelotoxic chemotherapy increase the risk of severe infections (grade 3-4). In patients treated with novel agent-based regimens, the rate of severe

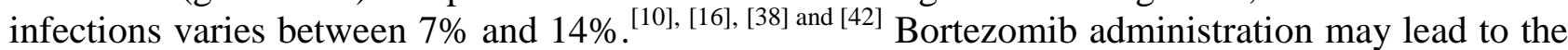
reactivation of herpes zoster virus ${ }^{79}$; in patients receiving bortezomib, prophylaxis with acyclovir is recommended $^{84}$. For patients treated with corticosteroids or myelotoxic drugs, or those with a higher risk of severe infections, routine antibiotic prophylaxis is suggested during the first cycles. Early recognition of fever or signs and symptoms of infection should lead to prompt administration of broad spectrum antibiotics.

\subsubsection{Bone disease}

Skeletal involvement due to MM cells infiltration occurs in $80 \%$ of MM patients, causing pathological fractures and pain, spinal cord compression and hypercalcemia. ${ }^{1}$ Biphosphonates, such as oral clodronic acid and intravenous pamidronic and zoledronic acid, are indicated to prevent bone disease. Zoledronic acid reduced skeletal-related events more than clodronic acid, with the advantage of longer PFS and OS. ${ }^{[85]}$ and ${ }^{[86]}$ Both zoledronic and pamidronic acid are effective in decreasing skeletal-related events ${ }^{87}$; recently, no efficacy difference was seen with pamidronate administered at either 30 or $90 \mathrm{mg}$. In patients with mild to moderate renal impairment (30$60 \mathrm{~mL} / \mathrm{min}$ of creatinine clearance), dose reductions of zoledronic acid are recommended; in case of severe renal impairment $(<30 \mathrm{~mL} / \mathrm{min}$ of creatinine clearance), pamidronic acid should be preferred. $^{88}$ Therapy with bisphosphonates should last approximately 2 years to limit the risk of osteonecrosis of the jaw. ${ }^{89}$ Bone pain can be managed both pharmacologically and with local, fractioned radiotherapy. Analgesia should be firstly provided with non-opiod drugs (avoiding nonsteroidal antiinflammatory drugs); if pain persists, opiod drugs should be used. Lytic lesions causing bone instability may be treated with preventive orthopedic stabilization, vertebroplasty may be indicated to reduce pain due to vertebral fractures.

\section{Conclusions}

The combination of novel agents, bortezomib and IMiDs, with conventional chemotherapy has deeply improved outcome in elderly patients. The attainment of a profound and sustained cytoreduction proved to be a predictor of longer outcome. An induction regimen associated with a high probability of $\mathrm{CR}$, and a continuous therapy with IMiDS or proteasome inhibitors prolong remission duration and improve outcome. A careful assessment of comorbidities, frailty and disability is essential to optimize treatment efficacy and reduce the frequency of adverse events. For very fit elderly patients, a sequential approach consisting of induction regimens incorporating novel agents, followed by reduced intensity ASCT and consolidation/maintenance is a valid therapeutic option. The standard of care for elderly patients not eligible for transplantation includes regimens with proteasome inhibitors, IMiDs, corticosteroids or alkylating agents in different combinations. In elderly unfit patients, a gentler approach with 2-drug regimen and a lower dose intensity should be adopted to avoid discontinuation and maximize treatment efficacy. In the relapse setting, the new proteasome inhibitor carfilzomib and the third generation IMiD pomalidomide, showed a great efficacy in patients relapsed/refractory to induction treatments. Newer agents, such as new oral proteasome inhibitors, monoclonal antibodies, and histone deacetylase inhibitors are currently under evaluation in clinical trials.

\section{Conflicts of interest}

Dr. Palumbo reports receiving consultancy fees and honoraria from Amgen, Bristol-Myers Squibb, Celgene, Janssen, Millenium, Onyx. Roberto Mina has no conflicts of interest. 


\section{Acknowledgment}

The authors thank the editorial assistant Giorgio Schirripa,

\section{References}

1. A. Palumbo, K. Anderson

Multiple myeloma

N Engl J Med, 364 (11) (2011), pp. 1046-1060

2. H. Brenner, A. Gondos, D. Pulte

Recent major improvement in long-term survival of younger patients with multiple myeloma

Blood, 111 (5) (2008), pp. 2521-2526

3. J.J. Keats, M. Chesi, J.B. Egan, V.M. Garbitt, S.E. Palmer, E. Braggio, et al.

Clonal competition with alternating dominance in multiple myeloma

Blood, 120 (5) (2012), pp. 1067-1076

4. J.B. Egan, C.-X. Shi, W. Tembe, A. Christoforides, A. Kurdoglu, S. Sinari, et al.

Whole-genome sequencing of multiple myeloma from diagnosis to plasma cell leukemia reveals genomic initiating events, evolution, and clonal tides

Blood, 120 (5) (2012), pp. 1060-1066

5. G.J. Morgan, M.F. Kaiser

How to use new biology to guide therapy in multiple myeloma

Hematology Am Soc Hematol Educ Program, 2012 (2012), pp. 342-349

6. S.Z. Usmani, J. Crowley, A. Hoering, A. Mitchell, S. Waheed, B. Nair, et al.

Improvement in long-term outcomes with successive total therapy trials for multiple myeloma: are patients now being cured?

Leukemia, 27 (1) (2013), pp. 226-232

7. S.K. Kumar, J.H. Lee, J.J. Lahuerta, G. Morgan, P.G. Richardson, J. Crowley, et al. 
Risk of progression and survival in multiple myeloma relapsing after therapy with imids and bortezomib: a multicenter international myeloma working group study

Leukemia, 26 (1) (2012), pp. 149-157

8. H.J.K. Van de Velde, X. Liu, G. Chen, W. Deraedt, M. Bayssas

Complete response correlates with long-term survival and progression-free survival in high-dose therapy in multiple myeloma

Haematologica, 92 (10) (2007), pp. 1399-1406

9. F. Gay, A. Larocca, P. Wijermans, F. Cavallo, D. Rossi, R. Schaafsma, et al.

Complete response correlates with long-term progression-free and overall survival in elderly myeloma treated with novel agents: analysis of 1175 patients

Blood, 117 (11) (2011), pp. 3025-3031

10. A. Palumbo, S. Bringhen, D. Rossi, M. Cavalli, A. Larocca, R. Ria, et al.

Bortezomib-melphalan-prednisone-thalidomide followed by maintenance with bortezomib-thalidomide compared with bortezomib-melphalan-prednisone for initial treatment of multiple myeloma: a randomized controlled trial

J Clin Oncol, 28 (34) (2010), pp. 5101-5109

11. G.J. Morgan, W.M. Gregory, F.E. Davies, S.E. Bell, A.J. Szubert, J.M. Brown, et al. The role of maintenance thalidomide therapy in multiple myeloma: MRC Myeloma IX results and meta-analysis

Blood, 119 (1) (2012), pp. 7-15

12. A. Palumbo, S. Bringhen, M. Cavalli, R. Ria, M. Offidani, F. Patriarca, et al.

Bortezomib, melphalan, prednisone and thalidomide followed by maintenance with bortezomib and thalidomide (VMPT-VT) for initial treatment of elderly multiple myeloma patients: updated follow-up and impact of prognostic factors

ASH Annual Meeting Abstracts, 116 (21) (2010), p. 620

13. A. Palumbo, S. Bringhen, D. Rossi, M. Cavalli, R. Ria, S. Gentilini, et al.

Overall survival benefit for bortezomib-melphalan-prednisone-thalidomide followed by maintenance with bortezomib-thalidomide (VMPT-VT) versus bortezomib-melphalanprednisone (VMP) in newly diagnosed multiple myeloma patients

ASH Annual Meeting Abstracts, 120 (21) (2012), p. 200

14. A. Palumbo, R. Hajek, M. Delforge, M. Kropff, M.T. Petrucci, J. Catalano, et al. 
Continuous lenalidomide treatment for newly diagnosed multiple myeloma

N Engl J Med, 366 (19) (2012), pp. 1759-1769

15. P.M. Fayers, A. Palumbo, C. Hulin, A. Waage, P. Wijermans, M. Beksaç, et al.

Thalidomide for previously untreated elderly patients with multiple myeloma: metaanalysis of 1685 individual patient data from 6 randomized clinical trials

Blood, 118 (5) (2011), pp. 1239-1247

16. J.F. San Miguel, R. Schlag, N.K. Khuageva, M.A. Dimopoulos, O. Shpilberg, M. Kropff, et al.

Bortezomib plus melphalan and prednisone for initial treatment of multiple myeloma

N Engl J Med, 359 (9) (2008), pp. 906-917

17. M.-V. Mateos, A. Oriol, J. Martínez-López, N. Gutiérrez, A.I. Teruel, A. López de la Guía, et al.

Maintenance therapy with bortezomib plus thalidomide or bortezomib plus prednisone in elderly multiple myeloma patients included in the GEM2005MAS65 trial

Blood, 120 (13) (2012), pp. 2581-2588

18. A. Palumbo, S. Bringhen, H. Ludwig, M.A. Dimopoulos, J. Bladé, M.V. Mateos, et al.

Personalized therapy in multiple myeloma according to patient age and vulnerability: a report of the European Myeloma Network (EMN)

Blood, 118 (17) (2011), pp. 4519-4529

19. R. Niesvizky, J. Reeves, I. Flinn

Phase $3 \mathrm{~b}$ upfront study: interim results from a community-based prospective randomized trial evaluating three bortezomib-based regimens in elderly, newly diagnosed multiple myeloma patients

EHA Annual Meeting, 95 (2) (2010), p. 0358

20. N. Howlade, A. Noone, M. Krapcho, N. Neyman, R. Aminou, S.F. Altekruse, et al.

Seer Cancer Statistics Review, 1975-2009 (Vintage 2009 Populations)

National Cancer Institute, Bethesda, MD (2012) [http://seer.cancer.gov/csr/1975_2009_pops09/, based on November 2011 seer data submission, posted to the seer web site]

21. S.Y. Kristinsson, O. Landgren, P.W. Dickman, A.R. Derolf, M. Björkholm 
Patterns of survival in multiple myeloma: a population-based study of patients diagnosed in Sweden from 1973 to 2003

J Clin Oncol, 25 (15) (2007), pp. 1993-1999

22. L.F. Hutchins, J.M. Unger, J.J. Crowley, C.A. Coltman Jr., K.S. Albain

Underrepresentation of patients 65 years of age or older in cancer-treatment trials

N Engl J Med, 341 (27) (1999), pp. 2061-2067

23. L.P. Fried, C.M. Tangen, J. Walston, A.B. Newman, C. Hirsch, J. Gottdiener, et al.

Frailty in older adults: evidence for a phenotype

J Gerontol A Biol Sci Med Sci, 56 (3) (2001), pp. M146-156

24. M. Charlson, T.P. Szatrowski, J. Peterson, J. Gold

Validation of a combined comorbidity index

J Clin Epidemiol, 47 (11) (1994), pp. 1245-1251

25. A. Palumbo, S. Bringhen, M.T. Petrucci, P. Musto, F. Rossini, M. Nunzi, et al.

Intermediate-dose melphalan improves survival of myeloma patients aged 50 to 70: results of a randomized controlled trial

Blood, 104 (10) (2004), pp. 3052-3057

26. T. Facon, J.Y. Mary, C. Hulin, L. Benboubker, M. Attal, B. Pegourie, et al.

Melphalan and prednisone plus thalidomide versus melphalan and prednisone alone or reduced-intensity autologous stem cell transplantation in elderly patients with multiple myeloma (IFM 99-06): a randomised trial

Lancet, 370 (9594) (2007), pp. 1209-1218

27. C. Straka, K. Schafer-Eckart, F. Bassermann, B. Hertenstein, M. Engelhardt, H. Salwender, et al.

Prospective randomized trial of Len/Dex induction followed by tandem mel140 with autologous blood stem cell transplantation and Len maintenance versus continued therapy with Len/Dex in myeloma patients age 60-75 years: protocol-defined safety analysis after 100 patients

ASH Annual Meeting Abstracts, 120 (21) (2012), p. 2012

28. J.L. Harousseau, C. Mathiot, M. Attal, G. Marit, D. Caillot, M.M.M. Mohty, et al. 
Velcade/dexamethasone (Vel/D) versus $\mathrm{VAD}$ as induction treatment prior to autologous stem cell transplantation (ASCT) in newly diagnosed multiple myeloma (MM): updated results of the IFM 2005/01 trial

ASH Annual Meeting Abstracts, 110 (11) (2007), p. 450

29. D.M. Weber, C. Chen, R. Niesvizky, M. Wang, A. Belch, E.A. Stadtmauer, et al.

Lenalidomide plus dexamethasone for relapsed multiple myeloma in North America

N Engl J Med, 357 (21) (2007), pp. 2133-2142

30. A. Palumbo, F. Gay, P. Falco, C. Crippa, V. Montefusco, F. Patriarca, et al.

Bortezomib as induction before autologous transplantation, followed by lenalidomide as consolidation-maintenance in untreated multiple myeloma patients

J Clin Oncol, 28 (5) (2010), pp. 800-807

31. A. Palumbo, F. Cavallo, I. Hardan, B. Lupo, V. Redoglia, M. Levin, et al.

Melphalan/prednisone/lenalidomide (MPR) versus high-dose melphalan and autologous transplantation (MEL200) in newly diagnosed multiple myeloma (MM) patients $<65$ years: results of a randomized phase iii study

ASH Annual Meeting Abstracts, 118 (21) (2011), p. 3069

32. H. Ludwig, R. Hajek, E. Tóthová, J. Drach, Z. Adam, B. Labar, et al.

Thalidomide-dexamethasone compared with melphalan-prednisolone in elderly patients with multiple myeloma

Blood, 113 (15) (2009), pp. 3435-3442

33. C. Hulin, T. Facon, P. Rodon, B. Pegourie, L. Benboubker, C. Doyen, et al.

Efficacy of melphalan and prednisone plus thalidomide in patients older than 75 years with newly diagnosed multiple myeloma: IFM 01/01 trial

J Clin Oncol, 27 (22) (2009), pp. 3664-3670

34. A. Palumbo, S. Bringhen, T. Caravita, E. Merla, V. Capparella, V. Callea, et al.

Oral melphalan and prednisone chemotherapy plus thalidomide compared with melphalan and prednisone alone in elderly patients with multiple myeloma: randomised controlled trial

Lancet, 367 (9513) (2006), pp. 825-831

35. P. Wijermans, M. Schaafsma, F. Termorshuizen, et al. 
Phase III study of the value of thalidomide added to melphalan plus prednisone in elderly patients with newly diagnosed multiple myeloma: the HOVON 49 study

J Clin Oncol, 28 (19) (2010), pp. 3160-3166

36. A. Waage, P. Gimsing, P. Fayers, et al.

Melphalan and prednisone plus thalidomide or placebo in elderly patients with multiple myeloma

Blood, 116 (9) (2010), pp. 1405-1412

37. M. Beksac, R. Haznedar, T. Firatli-Tuglular, H. Ozdogu, I. Aydogdu, N. Konuk, et al.

Addition of thalidomide to oral melphalan/prednisone in patients with multiple myeloma not eligible for transplantation: results of a randomized trial from the Turkish Myeloma Study Group

Eur J Haematol, 86 (1) (2011), pp. 16-22

38. A. Palumbo, A. Waage, C. Hulin, M. Beksac, S. Zweegman, F. Gay, et al.

Safety of thalidomide in newly diagnosed elderly myeloma patients: a meta-analysis of data from individual patients in six randomized trials

Haematologica, 98 (1) (2013), pp. 87-94

39. G.J. Morgan, F.E. Davies, W.M. Gregory, N.H. Russell, S.E. Bell, A.J. Szubert, et al.

Cyclophosphamide, thalidomide, and dexamethasone (CTD) as initial therapy for patients with multiple myeloma unsuitable for autologous transplantation

Blood, 118 (5) (2011), pp. 1231-1238

40. M. Dimopoulos, A. Spencer, M. Attal, H.M. Prince, J.L. Harousseau, A. Dmoszynska, et al.

Lenalidomide plus dexamethasone for relapsed or refractory multiple myeloma

N Engl J Med, 357 (21) (2007), pp. 2123-2132

41. J.A. Zonder, J. Crowley, M.A. Hussein, V. Bolejack, D.F. Moore, B.F. Whittenberger, et al.

Superiority of lenalidomide (Len) plus high-dose dexamethasone (HD) compared to HD alone as treatment of newly-diagnosed multiple myeloma (NDMM): results of the randomized, double-blinded, placebo-controlled SWOG trial S0232

ASH Annual Meeting Abstracts, 110 (11) (2007), p. 77 
42. S.V. Rajkumar, S. Jacobus, N.S. Callander, R. Fonseca, D.H. Vesole, M.E. Williams, et al.

Lenalidomide plus high-dose dexamethasone versus lenalidomide plus low-dose dexamethasone as initial therapy for newly diagnosed multiple myeloma: an open-label randomised controlled trial

Lancet Oncol, 11 (1) (2010), pp. 29-37

43. J.F. San Miguel, R. Schlag, N.K. Khuageva, M.A. Dimopoulos, O. Shpilberg, M. Kropff, et al.

Continued overall survival benefit after 5 years' follow-up with bortezomib-melphalanprednisone (VMP) versus melphalan-prednisone (MP) in patients with previously untreated multiple myeloma, and no increased risk of second primary malignancies: final results of the phase 3 vista trial

ASH Annual Meeting Abstracts, 118 (21) (2011), p. 476

44. M.-V. Mateos, A. Oriol, J. Martínez-López, N. Gutiérrez, A.I. Teruel, R. de Paz, et al.

Bortezomib, melphalan, and prednisone versus bortezomib, thalidomide, and prednisone as induction therapy followed by maintenance treatment with bortezomib and thalidomide versus bortezomib and prednisone in elderly patients with untreated multiple myeloma: a randomised trial

Lancet Oncol, 11 (10) (2010), pp. 934-941

45. R. Niesvizky, I.W. Flinn, R. Rifkin, N. Gabrail, V. Charu, B. Clowney, et al.

Efficacy and safety of three bortezomib-based combinations in elderly, newly diagnosed multiple myeloma patients: results from all randomized patients in the communitybased, phase $3 \mathrm{~b}$ UPFRONT study

ASH Annual Meeting Abstracts, 118 (21) (2011), p. 478

46. C.B. Reeder, D.E. Reece, V. Kukreti, C. Chen, S. Trudel, J. Hentz, et al.

Cyclophosphamide, bortezomib and dexamethasone induction for newly diagnosed multiple myeloma: high response rates in a phase II clinical trial

Leukemia, 23 (7) (2009), pp. 1337-1341

47. C.B. Reeder, D.E. Reece, V. Kukreti, C. Chen, S. Trudel, K. Laumann, et al.

Once- versus twice-weekly bortezomib induction therapy with cybord in newly diagnosed multiple myeloma

Blood, 115 (16) (2010), pp. 3416-3417 
48. P.G. Richardson, E. Weller, S. Lonial, A.J. Jakubowiak, S. Jagannath, N.S. Raje, et al.

Lenalidomide, bortezomib, and dexamethasone combination therapy in patients with newly diagnosed multiple myeloma

Blood, 116 (5) (2010), pp. 679-686

49. S. Kumar, I. Flinn, P.G. Richardson, P. Hari, N. Callander, S.J. Noga, et al.

Randomized, multicenter, phase 2 study (EVOLUTION) of combinations of bortezomib, dexamethasone, cyclophosphamide, and lenalidomide in previously untreated multiple myeloma

Blood, 119 (19) (2012), pp. 4375-4382

50. S. Bringhen, A. Larocca, D. Rossi, M. Cavalli, M. Genuardi, R. Ria, et al.

Efficacy and safety of once-weekly bortezomib in multiple myeloma patients

Blood, 116 (23) (2010), pp. 4745-4753

51. P. Moreau, H. Pylypenko, S. Grosicki, I. Karamanesht, X. Leleu, M. Grishunina, et al.

Subcutaneous versus intravenous administration of bortezomib in patients with relapsed multiple myeloma: a randomised, phase 3 , non-inferiority study

Lancet Oncol, 12 (5) (2011), pp. 431-440

52. P. Falco, F. Cavallo, A. Larocca, D. Rossi, T. Guglielmelli, A. Rocci, et al.

Lenalidomide-prednisone induction followed by lenalidomide-melphalan-prednisone consolidation and lenalidomide-prednisone maintenance in newly diagnosed elderly unfit myeloma patients

Leukemia, 27 (3) (2013), pp. 695-701

53. K.C. Anderson, R.A. Kyle, S.V. Rajkumar, A.K. Stewart, D. Weber, P. Richardson

Clinically relevant end points and new drug approvals for myeloma

Leukemia, 22 (2) (2008), pp. 231-239

54. E. Kastritis, A. Palumbo, M.A. Dimopoulos

Treatment of relapsed/refractory multiple myeloma

Semin Hematol, 46 (2) (2009), pp. 143-157 
55. S. Jagannath, P.G. Richardson, B. Barlogie, J.R. Berenson, S. Singhal, D. Irwin, et al.

Bortezomib in combination with dexamethasone for the treatment of patients with relapsed and/or refractory multiple myeloma with less than optimal response to bortezomib alone

Haematologica, 91 (7) (2006), pp. 929-934

56. S. Jagannath, B. Barlogie, J.R. Berenson, D.S. Siegel, D. Irwin, P.G. Richardson, et al.

Updated survival analyses after prolonged follow-up of the phase 2, multicenter CREST study of bortezomib in relapsed or refractory multiple myeloma

Br J Haematol, 143 (4) (2008), pp. 537-540

57. C. Touzeau, N. Blin, A. Clavert, V. Roland, M. Loirat, B. Tessoulin, et al.

Efficacy of lenalidomide plus dexamethasone in patients older than 75 years with relapsed multiple myeloma

Leuk Lymphoma, 53 (7) (2012), pp. 1318-1320

58. P.G. Richardson, P. Sonneveld, M.W. Schuster, D. Irwin, E.A. Stadtmauer, T. Facon, et al.

Bortezomib or high-dose dexamethasone for relapsed multiple myeloma

N Engl J Med, 352 (24) (2005), pp. 2487-2498

59. P.G. Richardson, P. Sonneveld, M. Schuster, D. Irwin, E.A. Stadtmauer, T. Facon, et al.

Extended follow-up of a phase 3 trial in relapsed multiple myeloma: final time-to-event results of the apex trial

Blood, 110 (10) (2007), pp. 3557-3560

60. A. Palumbo, O. Sezer, R. Kyle, J.S. Miguel, R.Z. Orlowski, P. Moreau, et al.

International Myeloma Working Group guidelines for the management of multiple myeloma patients ineligible for standard high-dose chemotherapy with autologous stem cell transplantation

Leukemia, 23 (10) (2009), pp. 1716-1730

61. M. Wang, M.A. Dimopoulos, C. Chen, M.T. Cibeira, M. Attal, A. Spencer, et al. 
Lenalidomide plus dexamethasone is more effective than dexamethasone alone in patients with relapsed or refractory multiple myeloma regardless of prior thalidomide exposure

Blood, 112 (12) (2008), pp. 4445-4451

62. S. Singhal, D.S. Siegel, T. Martin, R. Vij, L. Wang, A.J. Jakubowiak, et al.

Integrated safety from phase 2 studies of monotherapy carfilzomib in patients with relapsed and refractory multiple myeloma (MM): an updated analysis

ASH Annual Meeting Abstracts, 118 (21) (2011), p. 1876

63. S. Jagannath, R. Vij, K. Stewart, G. Somlo, A. Jakubowiak, S. Trudel, et al.

Final results of PX-171-003-A0, part 1 of an open-label, single-arm, phase II study of carfilzomib (CFZ) in patients (pts) with relapsed and refractory multiple myeloma (MM)

J Clin Oncol, 27 (Suppl. 15 s) (2009) [abstr 8504]

64. D.S. diCapua Siegel, T. Martin, M. Wang, R. Vij, A.J. Jakubowiak, S. Jagannath, et al.

Results of PX-171-003-A1, an open-label, single-arm, phase 2 (Ph 2) study of carfilzomib (CFZ) in patients (pts) with relapsed and refractory multiple myeloma (MM)

ASH Annual Meeting Abstracts, 116 (21) (2010), p. 985

65. R. Vij, M. Wang, J.L. Kaufman, S. Lonial, A.J. Jakubowiak, A.K. Stewart, et al.

An open-label, single-arm, phase 2 (PX-171-004) study of single-agent carfilzomib in bortezomib-naïve patients with relapsed and/or refractory multiple myeloma

Blood, 119 (24) (2012), pp. 5661-5670

66. W. Bensinger, M. Wang, R.Z. Orlowski, M. Alsina, T. Martin, S. Singhal, et al.

Dose-escalation study of carfilzomib (CFZ) plus lenalidomide (LEN) plus low-dose dexamethasone (DEX) (CRd) in relapsed/refractory multiple myeloma (R/R MM)

J Clin Oncol, 28 (15) (2010), p. 8029

67. A. Palumbo, A. Larocca, V. Montefusco, D. Rossi, A.M. Carella, R. Mina, et al.

Pomalidomide cyclophosphamide and prednisone (PCP) treatment for relapsed/refractory multiple myeloma

ASH Annual Meeting Abstracts, 120 (21) (2012), p. 446

68. T.M. Mark, A. Boyer, A.C. Rossi, M. Shah, R.N. Pearse, F. Zafar, et al. 
CLAPD (clarithromycin, pomalidomide, dexamethasone) therapy in relapsed or refractory multiple myeloma

ASH Annual Meeting Abstracts, 120 (21) (2012), p. 77

69. G. Birgegård, P. Gascón, H. Ludwig

Evaluation of anaemia in patients with multiple myeloma and lymphoma: findings of the European Cancer Anaemia Survey

Eur J Haematol, 77 (5) (2006), pp. 378-386

70. National comprehensive cancer network (NCCN)

NCCN Clinical Practice Guidelines In Oncology ${ }^{\mathrm{TM}}$ cancer- and chemotherapy-induced anemia (version 2.2011)

http://www.nccn.org/professionals/physician_gls/pdf/anemia.pdf

71. A. Palumbo, J. Bladé, M. Boccadoro, C. Palladino, F. Davies, M. Dimopoulos, et al.

How to manage neutropenia in multiple myeloma

Clin Lymphoma Myeloma Leuk, 12 (1) (2012), pp. 5-11

72. F. Gay, A. Palumbo

Management of older patients with multiple myeloma

Blood Rev, 25 (2) (2011), pp. 65-73

73. P.G. Richardson, H. Briemberg, S. Jagannath, P.Y. Wen, B. Barlogie, J. Berenson, et al.

Frequency, characteristics, and reversibility of peripheral neuropathy during treatment of advanced multiple myeloma with bortezomib

J Clin Oncol, 24 (19) (2006), pp. 3113-3120

74. M. Delforge, J. Bladé, M.A. Dimopoulos, T. Facon, M. Kropff, H. Ludwig, et al.

Treatment-related peripheral neuropathy in multiple myeloma: the challenge continues

Lancet Oncol, 11 (11) (2010), pp. 1086-1095

75. A. Palumbo, T. Facon, P. Sonneveld, J. Bladè, M. Offidani, F. Gay, et al.

Thalidomide for treatment of multiple myeloma: 10 years later

Blood, 111 (8) (2008), pp. 3968-3977 
76. B. Barlogie, R. Desikan, P. Eddlemon, T. Spencer, J. Zeldis, N. Munshi, et al.

Extended survival in advanced and refractory multiple myeloma after single-agent thalidomide: identification of prognostic factors in a phase 2 study of 169 patients

Blood, 98 (2) (2001), pp. 492-494

77. P.G. Richardson, R.L. Schlossman, E. Weller, T. Hideshima, C. Mitsiades, F. Davies, et al.

Immunomodulatory drug CC-5013 overcomes drug resistance and is well tolerated in patients with relapsed multiple myeloma

Blood, 100 (9) (2002), pp. 3063-3067

78. A. Palumbo, S.V. Rajkumar, M.A. Dimopoulos, P.G. Richardson, J. San Miguel, B. Barlogie, et al.

Prevention of thalidomide- and lenalidomide-associated thrombosis in myeloma

Leukemia, 22 (2) (2008), pp. 414-423

79. R. Alexanian, M.A. Dimopoulos, K. Delasalle, B. Barlogie

Primary dexamethasone treatment of multiple myeloma

Blood, 80 (4) (1992), pp. 887-890

80. M.A. Dimopoulos, P.G. Richardson, R. Schlag, N.K. Khuageva, O. Shpilberg, E. Kastritis, et al.

VMP (bortezomib, melphalan, and prednisone) is active and well tolerated in newly diagnosed patients with multiple myeloma with moderately impaired renal function, and results in reversal of renal impairment: cohort analysis of the phase III VISTA study

J Clin Oncol, 27 (36) (2009), pp. 6086-6093

81. M.A. Dimopoulos, E. Terpos, A. Chanan-Khan, N.K. Khuageva, O. Shpilberg, E. Kastritis, et al.

Renal impairment in patients with multiple myeloma: a consensus statement on behalf of the International Myeloma Working Group

J Clin Oncol, 28 (33) (2010), pp. 4976-4984

82. Celgene corporation

Revlimid package insert. Summit, NJ

available at: http://www.revlimid.com/pdf/revlimid_pi.pdf [accessed July 2012] 
83.A. Palumbo, F. Gay

How to treat elderly patients with multiple myeloma: combination of therapy or sequencing

Hematology Am Soc Hematol Educ Program (2009), pp. 566-577

84. A. Chanan-Khan, P. Sonneveld, M.W. Schuster, E.A. Stadtmauer, T. Facon, J.L. Harousseau, et al.

Analysis of herpes zoster events among bortezomib-treated patients in the phase III APEX study

J Clin Oncol, 26 (29) (2008), pp. 4784-4790

85.G.J. Morgan, F.E. Davies, W.M. Gregory, K. Cocks, S.E. Bell, A.J. Szubert, et al.

First-line treatment with zoledronic acid as compared with clodronic acid in multiple myeloma (MRC Myeloma IX): a randomised controlled trial

Lancet, 376 (9757) (2010), pp. 1989-1999

86. G.J. Morgan, J.A. Child, W.M. Gregory, A.J. Szubert, K. Cocks, S.E. Bell, et al.

Effects of zoledronic acid versus clodronic acid on skeletal morbidity in patients with newly diagnosed multiple myeloma (MRC myeloma IX): secondary outcomes from a randomised controlled trial

Lancet Oncol, 12 (8) (2011), pp. 743-752

87. L.S. Rosen, D. Gordon, M. Kaminski, A. Howell, A. Belch, J. Mackey, et al.

Long-term efficacy and safety of zoledronic acid compared with pamidronate disodium in the treatment of skeletal complications in patients with advanced multiple myeloma or breast carcinoma: a randomized, double-blind, multicenter, comparative trial

Cancer, 98 (8) (2003), pp. 1735-1744

88. R.A. Kyle, G.C. Yee, M.R. Somerfield, P.J. Flynn, S. Halabi, S. Jagannath, et al.

American Society of Clinical Oncology 2007 clinical practice guideline update on the role of bisphosphonates in multiple myeloma

J Clin Oncol, 25 (17) (2007), pp. 2464-2472

89. E. Terpos, O. Sezer, P.I. Croucher, R. García-Sanz, M. Boccadoro, J. San Miguel, et al.

The use of bisphosphonates in multiple myeloma: recommendations of an expert panel on behalf of the European Myeloma Network 
Ann Oncol, 20 (8) (2009), pp. 1303-1317 